\title{
A study to assess the effect of reminiscence therapy on psychological well- being, depression, and loneliness among elderly in selected old age homes of Mysore
}

\author{
Sharath $\mathbf{S}^{1}$, Nuthan Raj ${ }^{2 *}$ \\ ${ }^{1,2}$ Master Trainer, Dept. of Community Health Nursing, Regional Health and Family Welfare Training Center, Mysore, \\ Karnataka, India
}

*Corresponding Author: Nuthan Raj

Email: sharathmallappa@gmail.com

\begin{abstract}
In the present study to assess the effect of reminiscence therapy on psychological well-being, depression, and loneliness among elderly in selected old age homes of Mysore. a non-equivalent pre-test and post-test control group quasi experimental design was adopted. The samples were selected by adopting the non-probability convenience sampling technique. The sample consisted of 70 elderly staying in selected old age homes of Mysore, out of which 35 each in experimental and control group. The tool used for the data collection was Standardized geriatric depression scale to assess depression, Standardized Affect balance scale to measure psychological well-being, and Standardized UCLA loneliness scale to assess loneliness. On day1, 2, \& 3 psychological well-being, depression, and loneliness were pre tested both in experimental and control group. On day $4,6,8,10,12, \& 14$ the reminiscence therapy were administered to experimental group. On day 22, 23, \&24 post test was conducted respectively in both groups. Both descriptive and inferential statistics were used to analyse the data . Findings of the study revealed that there is a significant reduction in the post test mean depression, and loneliness scores of elderly in experimental group than the control group as evident from the ' $t$ ' value 5.365, and 9.268 with post-test $\mathrm{df}$ ' $\mathrm{t}$ ' $(68)$ at 0.05 level of significance, and also there is a significant gain in the post test mean psychological score of elderly in experimental group than the control group as evident from the ' $t$ ' value 4.763 with post-test $\mathrm{df}$ ' $\mathrm{t}$ ' ${ }_{(68)}$ at 0.05 level of significance. There was no significant association found between psychological well-being, depression, and loneliness of elderly in old age homes and their selected personal variables viz. age, gender, marital status, education level, income, visits by family members and other chronic medical illness. The findings revealed that, pre-test depression, and loneliness scores of elderly in old age homes was more compared to post-test depression, and loneliness scores and also pre-test psychological well-being score of elderly in old age homes was less compared to post test in experimental group.
\end{abstract}

Keywords: Psychological well-being, Depression; Loneliness, Reminiscence therapy, Elderly.

\section{Introduction}

In the words of Seneca 'old age is an incurable disease,' but Sir. James Sterling Ross commented 'you don't heal old age, you protect it, you promote it, and you extend it. ${ }^{4}$

Depression in elderly people often goes untreated because many people think that depression is a normal part of aging and a natural reaction to chronic illness, loss and social transition. Elderly people do face noteworthy challenges to their connections through loss and also face medical vulnerability and mortality. For the elderly population depression can come in different sizes and shapes. Many elderly people and their families don't recognize the symptoms of depression, aren't aware that it is a medical illness and don't know how it is treated. Others may mistake the symptoms of depression as signs of: dementia, Alzheimer's disease, Arthritis, cancer, heart disease, Parkinson's, stroke or Thyroid disorders. Also, many older persons think that depression is a character flaw and are worried about being made fun of or of being humiliated. They may blame themselves for their illness and are too ashamed to get help. Others worry that treatment would be too costly ${ }^{10}$. Hence as a cost effective, Validation therapy, reminiscence therapy, and cognitive behavioural therapy are three of the major treatment approaches used in the emotional care of the elderly person. Among these, reminiscence therapy is successful in improving comprehension skills and in boosting selfesteem, to ease the feeling of depression and hopelessness, meeting psychological and emotional needs, and to enhance self-integration of elderly persons ${ }^{15}$. Reminiscence is highly associated with pleasure, security, health, and a feeling of belonging to a place ${ }^{16}$. From studies suggest that reminiscence therapy is helpful in improving overall psychological well-being and to prevent further psychological deterioration. 


\section{Objectives of the study}

1. To assess the psychological well-being, depression, and loneliness among elderly before and after reminiscence therapy.

2. To determine the effectiveness of reminiscence therapy in terms of increased psychological wellbeing and decreased depression and loneliness scores among elderly.

3. To determine the relationship between
a. Loneliness and psychological well-being
b. Psychological well-being and depression
c. Loneliness and depression
d. Scores among elderly of selected old age homes.

4. To find the association of the levels of loneliness, psychological well-being and depression of elderly with their selected personal variables.

\section{Hypothesis}

$\mathbf{H}_{1^{-}}$The mean post-test psychological well-being scores of elderly will be significantly higher than their mean pre-test scores among experimental and control group.

$\mathbf{H}_{2^{-}}$The mean post-test depression and loneliness scores of elderly will be significantly lower than their mean pre-test scores among experimental and control group.

$\mathbf{H}_{3}$ - The mean post-test psychological well-being scores of elderly who have undergone reminiscence therapy will be significantly higher than the mean post-test psychological well-being scores of elderly who have not undergone reminiscence therapy.

$\mathbf{H}_{4}$ - The mean post-test depression and loneliness scores of elderly who have undergone reminiscence therapy will be significantly lower than the mean posttest depression and loneliness scores of elderly who have not undergone reminiscence therapy.

$\mathbf{H}_{5}$ - There will be significant relationship between,

a. loneliness and psychological well-being

b. loneliness and depression

c. psychological well-being and depression

Scores among elderly of selected old age homes.

$\mathbf{H}_{6}$ - The levels of a) psychological well-being b) depression and c) loneliness among elderly will be significantly associated with their selected personal variables

\section{Materials and Methods \\ Research Approach}

An evaluative research approach was used for the present study as the study aimed at evaluating the effectiveness of reminiscence therapy on psychological well-being, depression, and loneliness among elderly in selected old age homes of Mysore

\section{Research Design}

Table 1: The research design chosen was Quasi experimental non-equivalent pre-test post-test control group design

\begin{tabular}{|c|c|c|c|}
\hline \multicolumn{4}{|c|}{ Schematic representation of research design } \\
\hline Groups & \begin{tabular}{|l} 
Day 1, \\
\end{tabular} & Day 4,6,8,10,12\&14 & Day 24 \\
\hline & \begin{tabular}{|l|} 
Pre test \\
\end{tabular} & Intervention & Post test \\
\hline Experimental group & $\begin{array}{l}\text { Assessment of } \\
\text { - Psychological wellbeing } \\
\text { - Depression } \\
\text { - Loneliness }\end{array}$ & Reminiscence therapy (60min) & $\begin{array}{l}\text { Assessment of } \\
\text { - Psychological wellbeing } \\
\text { - Depression } \\
\text { - Loneliness }\end{array}$ \\
\hline Control group & $\begin{array}{l}\text { Assessment of } \\
\text { - Psychological wellbeing } \\
\text { - Depression } \\
\text { - Loneliness } \\
\end{array}$ & Routine care & $\begin{array}{l}\text { Assessment of } \\
\text { - Psychological wellbeing } \\
\text { - Depression } \\
\text { - Loneliness }\end{array}$ \\
\hline
\end{tabular}

\section{Research Setting}

The study was conducted in Vasavi shanthi dhama, and Chithra trust old age homes of Mysore

\section{Population}

In the present study population was defined as the elderly above 60 years of age and staying in old age homes, of Mysore. 


\section{Sampling Technique}

The non-probability convenience sampling technique was used in the present study.

\section{Sample and Sample Size}

The sample for the study consisted of 70 elderly with 35 each in experimental and control group from selected old age homes, of Mysore.

\section{Sampling Criteria}

Elders above 60 years of age who are able to communicate and comprehend either Kannada or English are included in the study.

\section{Data collection techniques and instruments}

1. Proforma for selected personal variables

2. Standardized geriatric depression scale

3. Standardized Affect balance scale to measure psychological well-being

4. Standardized UCLA loneliness scale

\section{Statistical Methods}

1. Frequency and percentage distribution of elderly in experimental groups and control group according to their selected personal variables

2. Comparison of selected personal variables of elderly among experimental and control group

a. Chi-square test to establish the equivalence with regard to selected personal variables of elderly among experimental and control group

\section{Results}

Mean, standard deviation, median, and range of pre-test and post-test psychological well being scores of elderly in experimental and control group $\mathrm{N}=70$

Table 2

\begin{tabular}{|l|c|c|c|c|c|c|c|c|}
\hline \multicolumn{9}{|c|}{ Psychological well being scores } \\
\hline \multicolumn{1}{|c|}{ Pro-test } & \multicolumn{4}{c|}{ Post-test } \\
\hline Group & Mean & SD & Median & Range & Mean & SD & Median & Range \\
\hline Experimental $\mathrm{n}=35$ & 4.53 & \pm 1.308 & 5.00 & $1-6$ & 7.09 & \pm 1.525 & 7.00 & $4-9$ \\
\hline Control $\mathrm{n}=35$ & 4.86 & \pm 1.593 & 5.00 & $2-8$ & 5.31 & \pm 1.568 & 5.00 & $2-8$ \\
\hline
\end{tabular}

Mean, mean difference, standard deviation difference, SEMD, and independent' ${ }^{\prime}$ ' test for pre-test psychological well being scores of elderly among experimental and control group $\mathrm{N}=70$

Table 3

\begin{tabular}{|l|l|l|c|c|c|c|}
\hline \multicolumn{7}{|c|}{ Psychological well being scores } \\
\hline Proup & Mean & $\begin{array}{c}\text { Mean } \\
\text { difference }\end{array}$ & $\begin{array}{c}\text { SD } \\
\text { difference }\end{array}$ & SEMD & $\begin{array}{c}\text { Independent } \\
\text { 't' test }\end{array}$ & $\begin{array}{c}\text { Significance } \\
\text { at } 0.05 \text { level }\end{array}$ \\
\hline $\begin{array}{c}\text { Experimental } \\
\text { Vs } \\
\text { Control }\end{array}$ & 4.53 & 0.33 & 0.285 & 0.03 & 0.932 & N.S \\
\hline
\end{tabular}

${ }^{\prime} \mathrm{t}{ }_{(68)}=2.000, \mathrm{p}>0.05$

Mean, mean difference, standard deviation difference, SEMD, and paired ' $t$ ' test of pre-test and post-test mean psychological well being scores of elderly $n=70$ 
Table 4

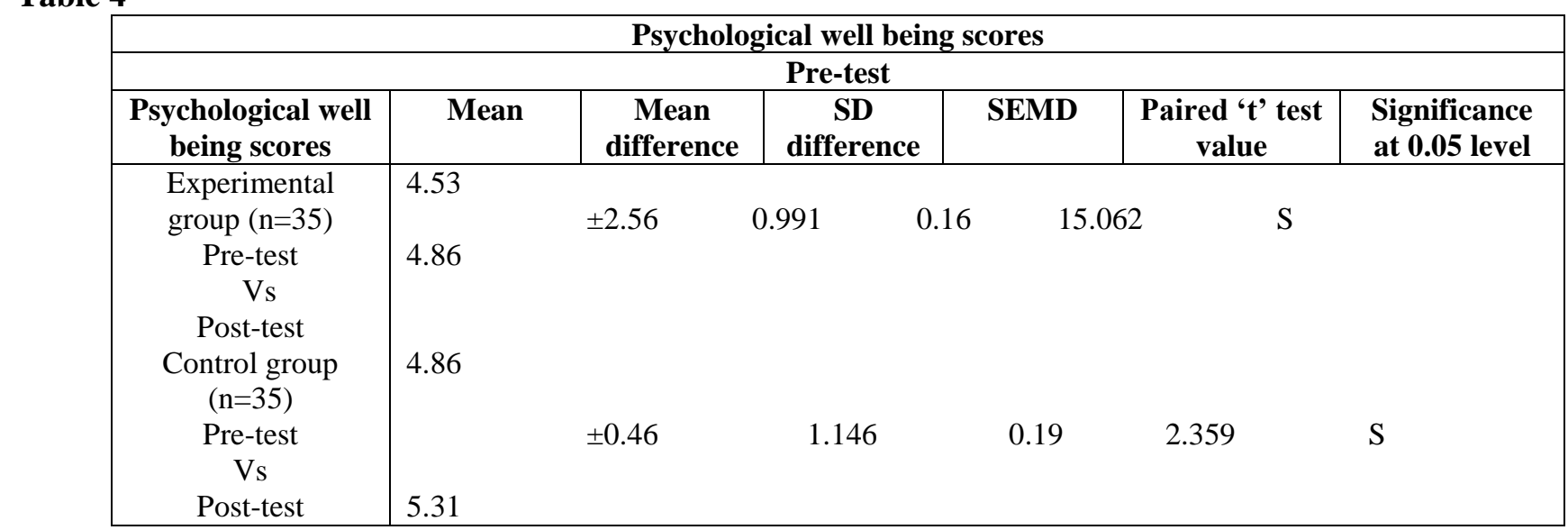

' $\mathrm{t}$ '

Paired' $t$ ' test values of psychological well being between Experimental group pre-test Vs post-test and Control group pre-test Vs post-test

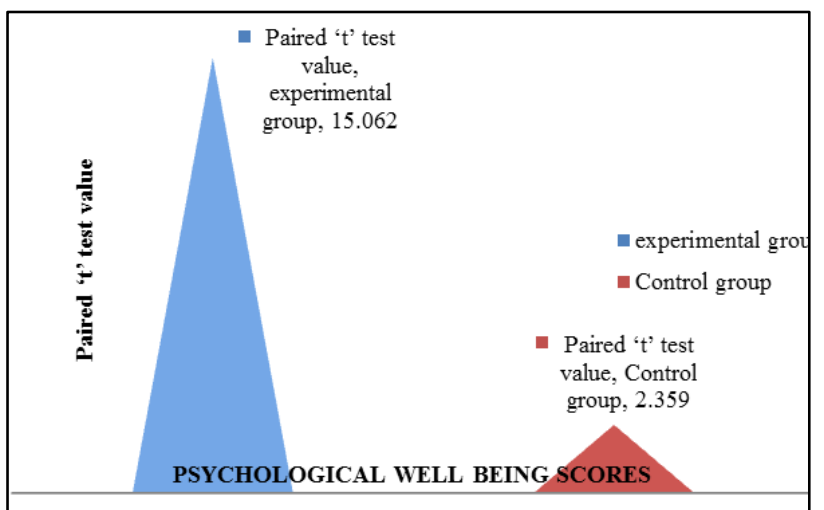

Fig. 1

Paired' $t$ ' test values of depression between Experimental group pretest Vs post-test and Control group pre-test Vs post-test

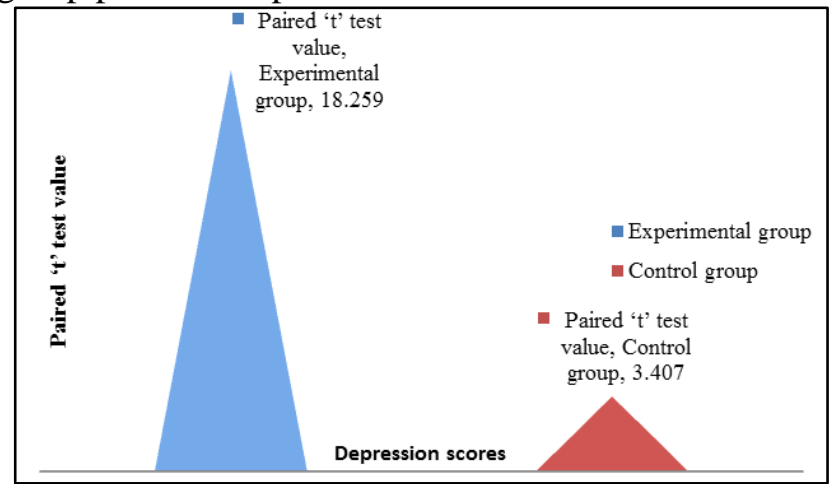

Fig. 2

Paired ' $t$ ' test values of loneliness between Experimental group pre-test Vs post-test and Control group pre-test Vs post-test

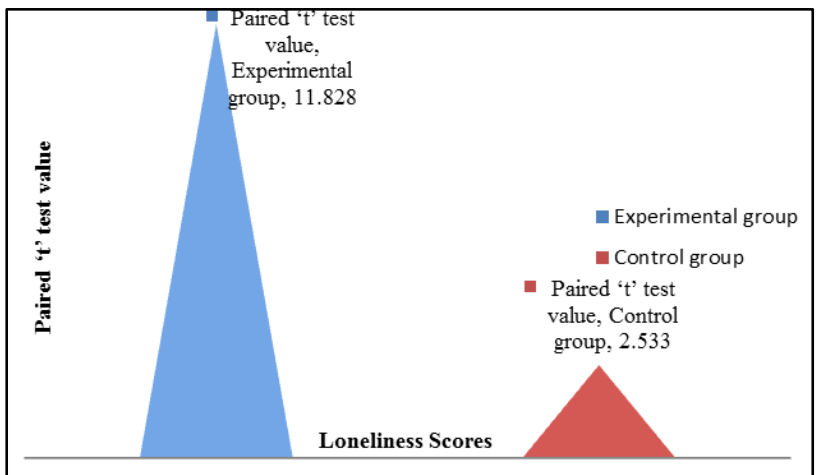

Fig. 3

\section{Discussion}

1. The post test mean psychological well being scores of elderly, who have received reminiscence therapy is significantly higher than their mean pre test psychological well being score ' $\mathrm{t}$ ' ${ }_{(34)}=15.062$ at 0.05 level of significance.

2. The mean difference between the post-test psychological well being mean scores of experimental and control group is 1.78, $\mathrm{t}(68)=4.763$ at 0.05 level of significance this indicates that there is a significance gain in psychological well being score in experimental group after undergoing reminiscence therapy.

3. Hence, the reminiscence therapy found to be an effective strategy to improve the psychological well being among elderly in old age homes. This findings were similar to other studies ${ }^{25,34,45.56}$ those revealed that the reminiscence therapy will improve the psychological well being among elderly.

4. The post test mean depression scores of elderly, who have received reminiscence therapy is significantly lower than their mean pre test 
depression score ' $\mathrm{t}$ ' ${ }_{(34)}=18.259$ at 0.05 level of significance.

5. The mean difference between the post-test depression mean scores of experimental and control group is 3.55 , ' $t$ ' $(68)=5.365$ at 0.05 level of significance these indicates there is a significance reduction in depression score in experimental group after undergoing reminiscence therapy.

6. Hence, the reminiscence therapy found to be an effective strategy to reduce the depression among elderly in old age homes. This findings were similar to other studies ${ }^{32,43,61}$ those revealed that the reminiscence therapy will decreases the depression among elderly.

7. The post test mean loneliness scores of elderly, who have received reminiscence therapy is significantly lower than their mean pre test loneliness scores ' $t$ ' ${ }_{(34)}=11.828$ at 0.05 level of significance.

8. The mean difference between the post-test loneliness mean scores of experimental and control group is 5.25 , ' $t$ ' $(8)=9.268$ at 0.05 level of significance these indicates there is a significance reduction in loneliness score in experimental group after undergoing reminiscence therapy.

9. Hence, the reminiscence therapy found to be an effective strategy to reduce the loneliness among elderly in old age homes. This findings were similar to other studies ${ }^{45,57,72,73}$ those revealed that the reminiscence therapy will decreases the loneliness among elderly

10. The correlation of coefficient value computed between pre-test loneliness and psychological well-being $r(69)=0.223$, loneliness and depression $r(69)=0.223$ and psychological wellbeing and depression $r(69)=0.223$ at 0.05 level of significance, shows that there is a positive relationship between psychological well-being, depression and loneliness. No published literature could be retrieved for comparison.
11. Computed chi-square values for association between pretest levels of depression, loneliness and psychological well-being among elderly in old age homes, was not found to be statistically significant at 0.05 levels for age, gender, marital status, education level, income, visits by family members and other chronic medical illness. Hence, it is inferred that elderly depression, loneliness and psychological well-being are not influenced by age, gender, marital status, education level, income, visits by family members and other chronic medical illness. No published literature could be retrieved for comparison

\section{Source of funding}

None.

\section{Conflict of interest}

None.

\section{References}

1. Old age solution, portal on technology solutions for elderly. An initiation of ministry of science and technology government of India brought to you by all India institutes of medical sciences. [Internet] [up dated 2009 Oct; cited 2011 jun]; available from: http/www.aims.org.ac.com

2. Patricia A, Tabloski. Gerontological nursing. $1^{\text {st }}$ ed. New Jersy: upper saddle river; 2006:11-12, 31

3. Bagchi K. Some Important Areas of Gerontological Research in India. Res Dev J 1998;4:2 \& 3

4. Park K. Park's text book of preventive and social medicine. $19^{\text {th }}$ ed. Bhanot publishers 2007

5. Chiang KJ, Chu H, Chang HJ. The effects of reminiscence therapy on psychological well-being, depression, and loneliness among the institutionalized aged. Int J Geriatric Psychiatry 2010;25(4):380-8

6. Smiltzer SC, Bare BG. Medical surgical nursing, $10^{\text {th }}$ ed. Philadelphia: Lippincott; 2000

How to cite: Sharath $\mathrm{S}$, Raj N, A study to assess the effect of reminiscence therapy on psychological wellbeing, depression, and loneliness among elderly in selected old age homes of Mysore. IP J Paediatr Nurs Sci 2020;3(1):19-23. 